\title{
MOTIF MERANTAU DALAM KABA
}

\author{
Haris Septian \\ Fakultas Ilmu Budaya Universitas Andalas
}

\begin{abstract}
This article describes the motives of Minangkabau people to merantau in kaba. Through intrinsic analysis, the analysis of kaba was continued using the socio-literary approach based on the sociology of the Minangkabau community

The motive of merantau in kaba are (1) cultural factors, (2) economic factors, (3) deepening knowledge, (4) social factors, and (5) accompanying the husband. The professionals involved in the majority are trading. The area that is the destination of nomads is cities with a high level of the trade such as the City of Bukittinggi, the City of Padang, and the City of Medan.
\end{abstract}

Keywords: kaba, merantau, Minangkabau

\section{PENGANTAR}

Kaba Minangkabau dibangun dari latar sosial budaya Minangkabau. Unsur-unsur tersebut sengaja dipadukan pengarang dan dibuat mirip dengan dunia yang nyata lengkap dengan peristiwa-peristiwa di dalamnya, sehingga tampak seperti sungguh ada dan terjadi, dan di situ terselip juga motif-motif peristiwa.

Merantau adalah istilah Melayu, Indonesia, dan Minangkabau yang sama arti dan pemakaiannya dengan akar kata rantau yang artinya pantai sepanjang (sungai) (Naim, 2013). Menurut Echols dan Shadily (dalam Kato, 2005), kata kerja rantau adalah merantau berarti pergi ke negeri lain, meninggalkan kampung halaman, berlayar melalui sungai, dan sebagainya. Namun menurut Naim (Naim, 2013), merantau adalah segela jenis perpindahan tempat tinggal, dekat atau jauh, dengan kemauan sendiri atau tidak, untuk sementara atau selamanya, dengan atau tujuan yang pasti, dengan atau tanpa maksud atau untuk kembali pulang, melembaga secara sosial dan kultural atau tidak.

Untuk mempertegas yang demikian, masyarakat Minangkabau dikenal punya tradisi merantau yang kuat. Pada tahun 1930 yang tercatat 1.928.322 orang Minangkabau yang tersebar diseluruh Indonesia dan sekitarnya (Naim, 2013). Mereka telah mengembara ke wilayah Asia Tenggara lainnya sejak berabad abad yang lalu yang disebabkan oleh alasan yang berbeda-beda. Keturunan mereka sampai aat ini masih ada bahkan berkembang di banyak tempat seperti Aceh, Riau, Sumatera Utara, Jambi, Bengkulu, Lampung atau wilayah Sumatera lainnya dan juga di Jawa, Sulawesi, Kalimantan, Nusa Tenggara, Malaysia, Singapura, Brunei, Filipina Selatan, dan lainlain. Faktor sebab-sebab orang merantau di Minangkabau ada sepuluh, yaitu faktor fisik : ekologi dan lokasi, faktor ekonomi dan demokrasi, faktor pendidikan, daya tarik kota, keresahan politik, faktor-faktor sosial, arus baru, faktor sosial bagi migrasi di antara masyarakat-masyarakat yang lain, faktor-faktor agregatif bagi migrasi, dan tipologi migrasi. Namun menurut Sjarifoedin (Sjarifoedin, 2014), ada empat faktor yang mendorong orang untuk merantau yaitu faktor budaya, faktor ekonomi, faktor perang, dan mendalami ilmu.

Peristiwa merantau merupakan salah satu peristiwa yang sering ditampilkan dalam kaba. Peristiwa merantau tersebut, terdapat motif seperti faktor ekonomi. Faktor ini diterdapat dalam kaba Si Gadih Ranti, kaba 


\section{Jurnal Elektronik WACANA ETNIK - Vol 8 No 1 April 2017, (1 - 12) \\ p ISSN 2089-8746, e ISSN 2302-7142}

Siti Risani, Siti Kalasun, dan Siti Baheram. Pendapat ini diperkuat oleh A.A. Navis (Navis, 1984) bahwa setiap orang, terutama anak muda akan senantiasa didorong dan ditarik agar pergi merantau oleh kaum kerabatnya dengan berbagai cara. Falsafah matrilineal Minangkabau mendorong anak muda agar kuat mencari harta kekayaan guna memperkukuh atau meningkatkan martabat kaum kekerabat agar setaraf dengan orang lain.

Faktor lain yang cukup menarik perhatian adalah pelaku merantau ini diantaranya termasuk perempuan. Biasanya pelaku merantau pada tempo dulu adalah laki-laki. Hal ini terdapat dalam kaba Si Gadih Kalasun dan kaba Siti Kalasun. Penyebab mereka merantau adalah menemani sang suami diperantauan. Pendapat ini diperkuat oleh Kato (Kato, 2005) yaitu faktor penyebab wanita ikut serta dalam proses merantau, salah satunya karena semakin banyak laki-laki membawa istrinya serta anak-anaknya ke daerah rantau.

\section{KERANGKA PEMIKIRAN DAN METODOLOGI}

Sosiologi merupakan ilmu pengetahuan kemasyarakatan umum yang merupakan hasil terakhir daripada perkembangan ilmu pengetahuan. Sosiologi lahir pada saat-saat terakhir perkembangan ilmu pengetahuan, oleh karena sosiologi didasarkan pada kemajuan-kemajuan yang telah dicapai ilmu-ilmu pengetahuan lainnya. Selanjutnya, Comte (dalam Soekarto, 2013) berpendapat bahwa sosiologi dibentuk berdasarkan pengamatan dan tidak pada spekulasi-spekulasi perihal keadaan masyarakat dan hasil-hasil observasi tersebut harus disusun secara sistematis dan metodologis

Faruk (Faruk, 2003) memberi pengertian bahwa sosiologi sastra sebagai studi ilmiah dan objektif mengenai manusia dalam masyarakat, studi mengenai lembaga dan proses-proses sosial. Selanjutnya, dikatakan bahwa sosiologi berusaha menjawab pertanyaan mengenai bagaimana masyarakat dimungkinkan, bagaimana cara kerjanya, dan mengapa masyarakat itu bertahan hidup. Pendekatan sosiologi sastra jelas merupakan hubungan antara satra dan masyarakat, artinya sastra adalah ungkapan perasaan masyarakat. Namun menurut Junus (Junus, 1984), karya sastra mewakili realitas sejarah. Karya sastra juga memberikan informasi mengenai aspek sosialbudaya pada masa tertentu dan pada suatu daerah tertentu sebagai diinterpretasikan oleh penulisnya. Karya sastra dianggap sebagai dokumen yang otentik, yang memberikan informasi tentang realitas atau sistem sosial.

Watt (dalam Damono, 1979) berpendapat bahwa sosiologi karya sastra mengkaji sastra sebagai cerminan masyarakat. Apa yang tersirat dianggap sebagai ceminkan atau menggambarkan kembali realitas yang terdapat dalam masyarakat.

Dalam hubungannya dengan merantau di Minangkabau, menurut Naim (dalam Sjarifoedin, 2014) merantau terkait dengan proses interaksi masyarakat Minangkabau dengan dunia luar. Hal ini menjadikan sebuah perjalanan mencari pengalaman dan geografis, dengan meninggalkan kampung halaman untuk mengadu nasib di negeri orang. Orang Minangkabau melakukan merantau dengan kemauan sendiri yang sudah tertanam diri sejak dia di didik di surau oleh tetua ataupun niniak mamak. Melihat proses ini semacam penjelajahan, proses hijrah, untuk membangun kehidupan yang lebih baik.

Sejalan dengan itu, merantau menjadikan mereka manusia yang mandiri, tidak hanya mandiri disegi ekonomi, tetapi mandiri disegi kepribadian (Sjarifoedin, 2014). Dengan kemauan sendiri untuk merantau agar menemukan kesuksesaan. Di sisi lain, dengan merantau akan menumbuhkan kecintaan, semangat untuk menghargai, menjaga dan melestarikan budaya dan adat yang ada pada kampung halaman. Ketika sudah jauh dari kampung halaman, para perantau akan melihat dan berpikir kalau budaya Minangkabau itu luar biasa dan akan lebih mencintainya daripada sebelumnya. Merantau merupakan sebuah cara ideal untuk mencapai kematangan 


\section{Jurnal Elektronik WACANA ETNIK - Vol 8 No 1 April 2017, (1 - 12) \\ p ISSN 2089-8746, e ISSN 2302-7142}

dan kesuksesaan bagi sebagian besar masyarakat Minangkabau. Dengan merantau, tidak hanya tentang harya kekayaan dan ilmu pengertahuan yang didapat, juga penghargaan dan kehormatan individual di tengah lingkungan adat. Di samping itu, banyak pula masyarakat Minangkabau untuk mencari perubahan dalam kehidupan. Misalnya, semua perantau awalya bekerja sebagai petani, tetapi diperantau lebih banyak diantara mereka yang beralih profesi. Mereka lebih memilih profesi lain ketimbangan profesi di kampung halaman.

Melalui analisis unsur instrinsik tokoh dan penokohan, alur, latar, dan tema terhadap objek penelitian, ditemukan muatan tentang merantau. Muatan merantau tersebut, dengan pendekatan sosiologi kemudian dianalisis hubungannya dengan kerangka pemikiran tentang merantau.

\section{TEMUAN DAN PEMBAHASAN}

Peristiwa merantau merupakan peristiwa yang sering diangkat dalam cerita kaba seperti dalam kaba Siti Baheram, Siti Kalasun, Siti Risani, Puti Nilam Cayo, Sabai Nan Aluih dan Si Gadih Ranti. Apalagi merantau menurut Hadler (Hadler, 2008) merupakan sebuah keharusan tetapi sekaligus diidealkan bagi anak muda yang menjelang dewasa. Merantau dalam adat istiadat, laki-laki Minangkabau harus meninggalkan kampung halaman mereka dan pergi ke rantau, ke dunia luar untuk mencari kekayaan, pendidikan, ataupun apa saja yang bernilai.

\section{FAKTOR BUDAYA}

Merantau merupakan suatu tradisi Minangkabau yang diwajibkan kepada para laki-laki. Selepas menempa ilmu pengetahuan di Surau mereka dilepaskan dan diwajibkan pergi dari kampung halaman untuk pergi merantau mencari kekayaan, kekuasaan, serta prestise baru. Disamping itu pun, di daerah tempat dia berasal, lakilaki tidak memiliki tidak memiliki kekuatan yang kuat. Jika demikian, Lekkerkerker (dalam Kato, 2005) berpendapat bahwa secara sadar atau tidak, laki-laki di Minangkabau selalu mencari tempat dimana dia dapat menemukan kebebasan dan kepribadiaannya.

Ketika merantau, mereka mencoba memperkaya dan menguatkan Alam Minangkabau. Ini merupakan konsep dasar dari faktor dan misi budaya dalam merantau. Dalam cerita kaba Siti Kalasun, tokoh Sabarudin pergi merantau dengan membawa beban budaya di pundaknya. Dia harus mencari harta kekayaan untuk kampung halamannya. Untuk menuntaskan itu semua, Sabarudin pergi merantau ke beberapa tempat untuk berdagang. Seperti kutipan di bawah ini.

“......lorong kapado Sabarudin, anak urang pandai manggaleh, mangaleh kain sudah, tidak ado hari tatabuang, hari bapakai samuonyo, hari Sanayan tibo di Baso, hari Sabtu Rabaa di Bukittinggi......” (KSK, hlm: 17)

“.....kepada Sabaradin, anak orang pandai berdagang, berdagang kain sudah, tidak ada hari terbuang, hari terpakai semuanya, hari Senin tiba di Baso, hari sabtu rabu di Bukittinggi..."

Kemudian, Sabarudin sukses pun dalam perantauannya. Dia mendapatkan prestise dan mengangkat pandangan masyarakat terhadap keluarganya serta kampung halamannya. Contohnya, banyaknya orang yang mengingikan Sabarudin untuk menjadi menantu. Contoh lainnya, dia menjadi salah satu pedagang yang sukses di perantauan. Dari situ, orang lain sangat disegani degan para pedagang yang berasal dari Minangkabau.

Dalam Kaba Si Gadih Ranti, tokoh Saman pergi merantau dengan alasan pertama, merantau merupakan sebuah tradisi yang wajib yang wajib dia lakukan sebagai laki-laki. Kedua, dia ingin memperbaiki kondisi 


\title{
Jurnal Elektronik WACANA ETNIK - Vol 8 No 1 April 2017, (1 - 12) \\ p ISSN 2089-8746, e ISSN 2302-7142
}

perekonomian keluarganya di kampung halaman. Dengan bermodalkan ilmu di Surau dan sekolah di Parabek, dia mencoba peruntungan dengan merantau dan mengambil profesi sebagai pedagang. Dengan menekuni satu pekerjaan, akhirnya Saman menjadi sukses. Orang kampung berpandang baik terhadap dia dan keluarganya. Banyak orang-orang yang mencoba menjadikan Saman menantu. Seperti kutipan di bawah ini.

“..... Manuruik cari ambo, kok Si Saman kito ambiak, anak dek mandeh Rawani, Bapaknyo Angku Kali di Subarang, inyo mangaleh di Padang. Manuruik kato urang, lapeh mangaji di Parabek, samo inyo di Padang, tidak ado pokok dari rumah, pancarian di ujuang jari, tiok bulan ado bakirim, balanjo mandeh jo adiaknyo." (KSGR, hlm: 21) “..... Menurut saya, kalau Si Saman jika pilih, anak dari Rawani, Bapaknya Angku kali di Subarang, Si Saman berdagang di Padang. Menurut kata orang, habis mengaji di Parabek, semasa dia di Padang, tidak ada modal dari rumah, pencarian di ujung jari, tiap bulan ada kiriman, belanja ibu dan adiknya,"

Dalam kaba Si Gadih Ranti, tokoh Jawair juga pergi merantau. Penyebab Jawair merantau adalah dia seorang laki-laki yang diwajibkan merantau, dia juga melestarikan salah satu budaya Minangkabau yaitu silek dan dia juga harus menghidupkan keluarganya.

\footnotetext{
"Manuruik kaba kato urang, sungguah mangaleh di kota Padang, kadaian gadang dikampung jawo, tiok malam maaja silek,...” (KSGR, hlm: 30)

"Menurut cerita kata orang, sungguh berdagang di kota Padang, toko besar dikampung jawa, tiap malam mengajar silat...."
}

Dalam kaba Siti Baheram terdapat juga peristiwa merantau. Tokoh Saidi, suami Siti Baheram pergi merantau ke Padang. Dia merantau di karena dia seorang laki-lak. Di Minangkabau laki-laki diwajibkan agar pergi merantau. penyebab lainnya yaitu dia harus menghidupi keluarganya, apalagi dia dalam cerita dalam kaba sudah memiliki anak. Seperti kutipan di bawah ini.

\begin{abstract}
"Mandanga kato minantunyo, manjawab mandeh Saidi, badarok mungko kalihatan," Anak kanduang Siti Baheram, kok kunun hanyo Saidi nantun, indak pulo inyo ka mari, mungkin ka darek Padang, jalannyo indak manantu, maklumlah jalan urang manggaleh, nagari indak nan jauh, dima rasaki ka bukak, inyo lah tibo pulo disinan. (KSB, hlm: 44) "Mendengar kata menantunya, menjawab ibu Saidi, gelisah muka kelihatan," Anak kanduang Siti baheram, kalau hanya Saidi itu, tidak pula dia kemari, mungkin ke Padang, jalannya tidak menentu, maklumlah jalan orang berdagang, nagari tidak yang jauh, dimana reseki yang terbuka, dia sudah tiba pula di sana.
\end{abstract}

Dalam kaba Siti Baheram, terdapat lagi peristiwa merantau. Pelakunya adalah si Bujang Juki dan Bujang Gambuik. Usia mereka kira-kira masih muda karena mereka belum menikah. Mereka merantau karena mereka seorang laki-laki yang masih muda dan menurut tradisi Minangkabau, mereka sangat ideal untuk merantau. penyebab lainnya yaitu mereka harus memperbaiki kondisi keluarga mereka. Seperti kutipan di bawah ini.

\footnotetext{
“Bakato si Bujang Juki, iyo kapado mandeh kanduang,” Manolah mandeh jonyo ambo, ka marilah mandeh den katokan, laikoh mandeh mandanga, urang baralek di Sungai Pasak, alek rami dek urang main. Di cubolah malah ka kian bisuak, kok untuang manang pamainan, tatabuih gadaian lamo, tabangkik batang tarandam, lamo marasai kok deh sanang, balasan paneh kok leh hujan”. (KSB, hlm: 21)

"Berkata si Bujang Juki, iya kepada ibu kandung," manalah ibu iya ibu
} 


\section{Jurnal Elektronik WACANA ETNIK - Vol 8 No 1 April 2017, (1 - 12) \\ p ISSN 2089-8746, e ISSN 2302-7142}

saya, ke marilah ibu saya katakana, kalau ibu mendengarkan, orang persta di Sungai Pasak, perayaan rami karena orang main.

Dicobalah untuk kesitu besok, kalau bernasib baik menang permainan, tertebus gadaian yang lama, terbangkit batang terandam, lama sengsara

kalau berubah senang, balasan panas kalau ada hujan."

\section{FAKTOR EKONOMI}

Faktor ekonomi merupakan salah satu faktor yang mempergaruhi besarnya jumlah perantau Minangkabau. Paradigma yang berkembang bahwa merantau dapat membuat perekonomian jadi lebih baik. Sejalan dengan itu, Naim (Naim, 2013) berpendapat karena kurangnya sarana kehidupan di Minangkabau yang mendesak penduduknya pergi merantau, oleh karena kehidupan di rantau lebih mudah didapat. Faktor ekonomi juga menjadi pendorong bila berimbang sarana kelangsungan hidup dengan jumlah penduduk yang bergantung kepadanya (masyarakat) mulai goyah dan itu bisa saja terjadi dalam cerita kaba.

Dalam cerita Kaba Siti Kalasun, terdapat proses merantau yang dipengaruhi oleh faktor ekonomi yang dilakukan oleh tokoh Sabarudin. Kesukaan merantau ini memang sudah ada dalam diri Sabarudin karena Haji Munaf, bapak Sabaruddin juga merantau sebelumnya. Diri yang belum menikah dan badan yang masih kepunyaan orangtua serta kondisi keluarga yang hidup sederhana membuat dia tidak bisa berdiam diri dikampung halaman dan mengharapkan semuanya dari orangtua. Ketika telah menyelesaikan pendidikan dan menuntut ilmu di Thawalib Parabek, Sabarudin pergi ke Kota Padang untuk berdagang dan ke beberapa daerah seperti di Bukittinggi dan Baso. Di Bukittinggi yang khususnya di daerah Aur Kuning, dimana hari pasarnya yaitu di hari rabu dan sabtu. Biasanya volume jual beli sangat tinggi.

Kebanyakan orang luar kota membeli dan jual dengan jumlah yang sangat besar. Begitu juga dengan di daerah Baso yang hari pasarnya di hari senin. Ketika hari pasar, aktivitas pedagang sangat tinggi. Mulai dari berjualan kecil-kecilan hingga besar.

“......lorong kapado Sabarudin, anak urang pandai manggaleh, mangaleh kain sudah, tidak ado hari tatabuang, hari bapakai samuonyo, hari Sanayan tibo di Baso, hari Sabtu Rabaa di Bukittinggi....." (KSK, hlm: 17)

“.....kepada Sabaradin, anak orang pandai berdagang, berdagang kain sudah, tidak ada hari terbuang, hari terpakai semuanya, hari Senin tiba di Baso, hari sabtu rabu di Bukittinggi..."

Selama perantauannya, Sabarudin belum bisa meningkatkan perekonomian keluarganya. Hal positif yang terjadi adalah nama keluarga menjadi baik di mata masyarakat dan mungkin saja banyak orang yang berebut untuk menjadikan dia sebagai menantu. Akhirnya Sabarudin menikah dengan Siti Kalasun.

Kaba Siti Kalasun, terdapat juga proses merantau yang dipengaruhi oleh faktor ekonomi yang dilakukan oleh Tokoh Haji Munaf ayah dari Sabarudin. Kondisi keluarga yang hidup sederhana membuatnya dia harus pergi jauh dari keluarga untuk merantau ke Kota Padang. Pekerjaan yang digelutin adalah berdagang. Hal ini terbukti dari perkataan Sutan Marajo Lelo dalam kaba. Seperti kutipan di bawah ini:

“Manjawab Sutan Marajo Lelo, "Lorong kapado Haji Munaf, samo mangaleh di Padang, tak ado urang elok itu, lapang dado hati barasiah.” (KSK, hlm: 43)

"Menjawab Sutan Marajo Lelo, "hadap kepada Haji Munaf, sama berdagang di Padang, tidak ada orang sebaik itu, lapang dada hati bersih." 


\section{Jurnal Elektronik WACANA ETNIK - Vol 8 No 1 April 2017, (1 - 12) \\ p ISSN 2089-8746, e ISSN 2302-7142}

Merantau yang dilakukan Haji Munaf cukup memberikan hal positif bagi keluarganya seperti dia dapat menyekolahkan anaknya (Sabarudin) hingga lulus di Thawalib Parabek. Serta keelokan dan kebaikan hatinya membuat dia menjadi orang yang terkenal di masanya.

Dalam kaba Si Gadih Ranti, Saman pergi merantau ke Padang untuk memperbaiki perekonomian keluarganya. Dengan ilmu yang dia dapat mulai dari di surau hingga bersekolah di Parabek dia aplikasi ke dalam usaha berdagang dia itu. Pada awalnya dia pergi merantau tanpa membawa modal sedikitpun dari rumah.

“..... Manuruik cari ambo, kok Si Saman kito ambiak, anak dek mandeh Rawani, Bapaknyo Angku Kali di Subarang, inyo mangaleh di Padang. Manuruik kato urang, lapeh mangaji di Parabek, samo inyo di Padang, tidak ado pokok dari rumah, pancarian di ujuang jari, tiok bulan ado bakirim, balanjo mandeh jo adiaknyo." (KSGR, hlm: 21)

“..... Menurut saya, kalau Si Saman jika pilih, anak dari Rawani, Bapaknya Angku kali di Subarang, Si Saman berdagang di Padang. Menurut kata orang, habis mengaji di Parabek, semasa dia di Padang, tidak ada modal dari rumah, pencarian di ujung jari, tiap bulan ada kiriman, belanja ibu dan adiknya,"

Setelah tiga tahun setelah kejadian Angku kapalo menyuruh dia untuk kerja rodi di Malalak, akhirnya Saman tambah sukses dengan usahanya dan mempunyai toko yang besar serta lengkap dengan isi-isinya mulai dari arlogi, lemari, kain-kain dan lain-lain untuk dijual.

"Birawari Bujang Saman, dek himaik balanjo jo rajin mangaleh, kadaian batambah gadang, manaruqh cukuik jo loji jam dinding, sarato barang kain-kain, kain kuto na haluih, kadaian sarupo toko Cino, langkok barang di dalamnyo, bacam-macam dalam lamari". . (KSGR, hlm: 69) "Birawari Bujang Saman, karena hemat dan rajin berdagang, toko bertambah besar, meletakkan cukup dengan jam arloji jam dinding, serta barang kain-kain, kain kuto yang halus, toko kayak toko Cina, lengkap barang di dalamnya, bermacam-macam dalam lemari.

Dalam kaba Siti Baheram tentang peristiwa merantau juga. Dalam kaba tersebut, Tokoh Saidi suami dari Siti Baheram pergi merantau ke tanah Padang untuk bedagang. Di mana ada orang yang ramai atau ada acara disuatu tempat, dia berada dan berdagang di sana. Seperti kutipan di bawah ini.

\footnotetext{
"Mandanga kato minantunyo, manjawab mandeh Saidi, badarok mungko kalihatan," Anak kanduang Siti Baheram, kok kunun hanyo Saidi nantun, indak pulo inyo ka mari, mungkin ka darek Padang, jalannyo indak manantu, maklumlah jalan urang manggaleh, nagari indak nan jauh, dima rasaki ka bukak, inyo lah tibo pulo disinan. (KSB, hlm: 44)

"Mendengar kata menantunya, menjawab ibu Saidi, gelisah muka kelihatan," Anak kanduang Siti baheram, kalau hanya Saidi itu, tidak pula dia kemari, mungkin ke Padang, jalannya tidak menentu, maklumlah jalan orang berdagang, nagari tidak yang jauh, dimana reseki yang terbuka, dia sudah tiba pula di sana.
}

Tokoh Bujang Juki yang durhaka kepada ibunya juga melakukan proses merantau. Ketika Juki akan pergi merantau, Juki meminta modal kepada ibunya dengan sikap yang tidak selayak anak lakukan. Dia menghalalkan segala cara untuk mendapatkan apapun dia inginkan dari ibunya. Juki pun tidak segan-segan untuk brsikap kasar kepada ibunya. Ibu Juki pun yang dari dahulunya selalu memenuhi kehendak Juki karena Juki adalah anak satusatunya. 


\section{Jurnal Elektronik WACANA ETNIK - Vol 8 No 1 April 2017, (1 - 12)}

p ISSN 2089-8746, e ISSN 2302-7142

Tujuan Juki merantau adalah untuk mengubah nasib keluarganya yang saat itu dilanda kemiskinan.

Karena ada Alek di Sungai Pasak dan ada juga permainan judinya, Juki mencoba kebuntungan dengan bermain judi. Seperti kutipan di bawah ini.

"Bakato si Bujang Juki, iyo kapado mandeh kanduang," Manolah mandeh jonyo ambo, ka marilah mandeh den katokan, laikoh mandeh mandanga, urang baralek di Sungai Pasak, alek rami dek urang main. Di cubolah malah ka kian bisuak, kok untuang manang pamainan, tatabuih gadaian lamo, tabangkik batang tarandam, lamo marasai kok deh sanang, balasan paneh kok leh hujan”. (KSB, hlm: 21)

"Berkata si Bujang Juki, iya kepada ibu kandung," manalah ibu iya ibu saya, ke marilah ibu saya katakana, kalau ibu mendengarkan, orang persta di Sungai Pasak, perayaan rami karena orang main.

Dicobalah untuk kesitu besok, kalau bernasib baik menang permainan, tertebus gadaian yang lama, terbangkit batang terandam, lama sengsara kalau berubah senang, balasan panas kalau ada hujan."

Dalam kaba Siti Risani, kehidupan yang sederhana membuat seorang Tuanku Imam Mudo ayahnya Siti

Risani pergi merantau untuk berdagang di pasar. Seperti kutipan di bawah ini.

“....awak surang tingga dirumah, kok mandeh pai ka ladang, inyo di jerok Tanjuang Subaliak, kok nan bungsu maantaan nasi, ayahnyo pai ka balai, namonyo urang baniago. (KSR, hlm: 13)

“....saya sendiri tinggal dirumah, kalau ibu pergi ke ladang, dia di Jerok Tanjung Subaliak, kalau adik pergi mengantar nasi, ayah pergi ke pasar, namanya juga berdagang.

Dalam kaba Siti Risani, terdapat proses merantau yang dipengaruhi faktor ekonomi yang dilakukan oleh

Tokoh Nasarudin. Peristiwa ini dimulai ketika Nasarudin dan Risani ingin dijodohkan oleh keluarga mereka masing-masing. Atas dasar mereka menolak hal itu, merekapun larikan diri dari kampung halaman.

Di perjalanan pun mereka menghabis begitu banyak uang. Dimulai dari biaya perjalanan mereka, biaya hidup diperjalanan, hingga biaya pernikahan mereka. Setelah menikah, mereka pergi ke Medan untuk menjalani hidup sebagai sepasang suami istri. Biaya kehidupan di Medan yang cukup tinggi, Nasarudin pun mencari pekerjaan. Akhirnya, di Kantor BPM Nasarudin bekerja dan di sana dulunya tempat Nasarudin bekerja.

"Alah sudah makan jo minum, lalu tagak sakutiko, iyolah Sutan

Nasarudin, mancaliak inyo ka gambar kota Medan, lalu bakto maso itu,"Adiak kanduang Siti Risani, ka marilah adiak tagak, lieklah gambar kota Medan, kok ka iyo juo wak ka kian,"

Kununlah Si Siti Risani, tagak sugiro maso itu, diliek malah gambar nantun, "Lai tampak dek adiak rumah gadang tu, nan talatak di tapi labuah, rancak nan bukan alang-alang, itulah kantua BPM, kunun di sanan ambo dahulu karajo, lai dapek surek baranti sacaro elok," kato Sutan Nasarudin.

Manjawab Si Siti Risani, "Tuan kanduang janyo ambo, kalau dipikia kiro-kiro, ditimbang awal jo akhia, dikana untuang badan kito, elok kito barangkek kito kini-kini, iyo ka Medan banda sapuluah, di sanan kito tingga......" (KST, hlm: 75)

Setelah selesai makan dan minum, lalu berdiri seketika, iyalah Sutan Nasarudin, melihat dia kegambar Kota Medan, lalu berkata dia ketika itu," adik kandung Siti Risani, ke marilah adik berdiri, lihatlah gambar Kota Medan, kalau jadi juga kita kesana." Dululah Si Siti Risani, berdiri segera ketika itu, di lihat yang gambar itu," apakah kelihatan oleh adik rumah gadang itu, yang terletak ditepi jalan, bagus yang bukan alng-alang, itulah kantor BPM, dahulunya disana saya 


\section{Jurnal Elektronik WACANA ETNIK - Vol 8 No 1 April 2017, (1 - 12) \\ p ISSN 2089-8746, e ISSN 2302-7142}

bekerja, ada dapat surat berhenti secara baik," kata Sutan Nasarudin.

Menjawab Si Siti Risani,'Tuan Kanduang kepunyaan saya, kalau dipikir

kira-kira, ditimbang awal dan akhir, diingat untung badan kita, baik kita berangkat kita sekarang, iya ke Medan Banda Sapuluah, disana kita tingga...."

"Adiak Kanduang Siti Risani, ado nan takana dikiro-kiro, nan taguriah di hati ambo, sakarang kini nangko, handak pai bajalan-jalan,

manjalang wakatu luhua, pai mancari tampek karajo, tolong malah dek Adiak jo doa, kok lai untuang kito ka elok, dapeklah karajo handaknyo, di tampek ambo bakarajo dulu." (KSR, hlm: 80)

"Adik Kandung Siti Risani, ada yang terpikir dikira-kira, yang terkena dihati saya, saat sekarang ini, hendak pergi berjalan-jalan, menjelang waktu zuhur, pergi mencari tempat kerja, tolong oleh Adik jo doa, kalau ada untung kita ke baik, dapatlah kerja hendaknya, ditempat saya bekerja dahulunya."

Berdasarkan kutipan di atas, dapat dilihat bagaimana Nasarudin memiliki tanggung jawab yang besar setelah dia menikah dengan Risani. Untuk biaya jangka pendek harus dipenuhi untuk bisa membuat dia bertahan di Kota Medan. Untuk jangka panjang pun dia harus dipenuhi juga, seperti punya rumah serta isi-isinya dan nanti juga dia akan mempunyai anak. Termasuk juga dengan biaya-biaya tidak terduga nantinya. Peluang terbesar dia untuk bisa memenuhi itu semua adalah dengan bekerja di kantor lamanya dan itu terletak di Medan.

Dengan cara yang hampir serupa, banyak rumah tangga Buton melakukan varietas migrasi ekonomi musiman (merantau) melintasi kepulauan (McWilliam, 2009). Selain itu, anggota bangsawan Palembang (kemas) adalah aktor penting dalam merantau. Pedagang kaya ini tidak hanya bertindak sebagai agen untuk layanan feri dari Bawean melalui Jawa ke Singapura, tetapi juga menjadi rentenir yang membayar di muka biaya perjalanan para migran dan, pajak keluar wajib bagi para migran yang meninggalkan pulau (Spaan, 1994).

\section{MENDALAMI ILMU}

Dalam kaba Si Gadih Ranti, terdapat proses merantau yang disebabkan oleh faktor pendidikan. Salah satu kunci sukses dalam perantauan Saman ke Kota Padang adalah dia seorang terpelajar. Saman awalnya merantau dahulu ke Parabek untuk mendapatkan ilmu pengetahuan dan belajar mengaji.

Manuruik kato urang, lapeh mangaji di Parabek, samo inyo di Padang, tidak ado pokok dari rumah, pancarian di ujuang jari, tiok bulan ado bakirim, balanjo mandeh jo adiaknyo." (KSGR, hlm: 21) Menurut kata orang, selesai mengaji di Parabek, semasa dia di Padang, tidak ada modal dari rumah, pencarian di ujung jari, tiap bulan ada kiriman, belanja ibu dan adiknya,"

Dalam kaba Siti Kalasun, tokoh Siti Kalasun orang Kampung nan Limo dahulunya pergi merantau untuk mendapatkan pendidikan. Sewaktu dalam cerita, untuk mendapatkan pendidikan yang bagus sedikit susah didapatkan. Masyarakat berlomba-lomba untuk mendapatkan pendidikan itu. Seandaikan ada peluang untuk mendapatkan pendidikan, tidak ada kata untuk menolaknya. Seperti apa yang terjadi pada tokoh Siti Kalasun yang merantau ke Parabek untuk mengaji dan belajar ilmu pengetahuan.

“....iyolah si Kalasun anak Rapiah, urang Guci Kampuang nan Limo, kamanakan Datuak Marajo, tidak pandai bajalan-jalan, tidak ado babaju rok, baju singkek tidak balangan, pakaiannyo babaju kuruang, lapeh mangaji di Parabek." (KSK, hlm: 15)

“....iyalah si Kalasun anak Rapiah, orang Guci Kampung nan Limo, 


\section{Jurnal Elektronik WACANA ETNIK - Vol 8 No 1 April 2017, (1 - 12) \\ p ISSN 2089-8746, e ISSN 2302-7142}

kemenakan Datuk Marajo, tidak bisa berjalan-jalan, tidak ada berbaju rok, baju singkat tidak berlengan, pakaiannya berbaju kurung, lepas mengaji di Parabek."

Merantau yang terjadi karena faktor pendidikan, terdapat lagi dalam kaba Siti Kalasun. Tokoh Sabarudin orang Kampung Pincuran Limo dahulunya pergi merantau untuk mendapatkan pendidikan yang bagus. Sabarudin merantau ke Parabek untuk mengaji dan belajar ilmu pengetahuan.

“....tidak barapo urang nan tahu, biaso gadang di Parabek, samo mangaji jo Kalasun, lapeh mangaji pai mangaleh, masuak pakan ka lua pakan." (KSK, hlm: 23)

“....tidak berapa orang yang tahu, biasa gadang di Parabek, sama mengaji dengan Kalasun, lepas mengaji pergi berdagang, masuk pasar kelar pasar."

Merantau yang terjadi karena faktor pendidikan, terdapat lagi dalam kaba Siti Kalasun. Tokoh Malin Saidi melakukan proses merantau untuk mendapatkan pendidikan yang bagus. Malin Saidi merantau ke Parabek untuk mengaji dan belajar ilmu pengetahuan. Seperti kutipan di bawah ini:

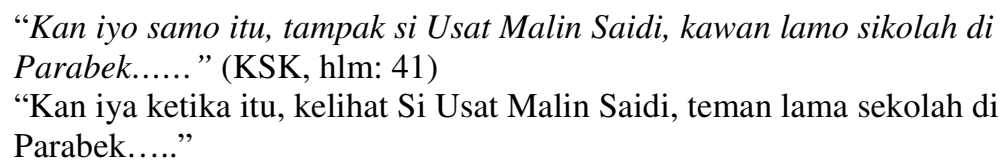

\section{FAKTOR-FAKTOR SOSIAL}

Dalam kaba Siti Risani tentang peristiwa merantau yang disebabkan oleh faktor-faktor sosial. Maksudnya, terjadi sebuah ketidak sepahaman antara para tokoh-tokoh dalam kaba seperti tokoh-tokoh dalam sebuah keluarga. Tokoh Siti Risani dan tokoh Nasurudin akan dijodohkan dengan jodoh pilihan keluarga masingmasing. Siti Risani akan dijodohkan dengan Hamzah Barudin St. Bagindo dan Nasarudin juga akan dijodohkan dengan Siti Arabainah. Mereka tidak menginginkan yang hal demikian. Akhirnya dengan rasa penuh penyelasan, Siti Risani dengan Nasarudin pergi dan meninggalkan kampung halaman masing-masing.

\footnotetext{
"Alah tibo ditangah laman, mamandang inyo ka labuah gadang, sanan disonsong dek Sutan Nasarudin, bajawek salam bapegang jari, nan tidak dilapehkan sampai ka ateh oto, maliek kapado arloji tangan, hari basarang laruik juo, kini lah pukua satu liwat saparampek, oto barangkek hanyo lai. (KSR, hlm. 54)

"ketika sudah tiba ditengah halaman, memandang dia kejalan besar, disitu dihampiri oleh Sutan Nasarudin, disambut salam berpegangan jari, yang tidak dilepaskan sampai diatas mobil, melihat ke jam tangan, hari sudah larut malam, sekarang sudah pukul satu lewat seperempat, mobil berangkat lagi.
}

Dalam kaba Puti Nilam Cayo, terdapat peristiwa merantau yang disebabkan karena rasa kemanusiaan dan persaudaraan dalam diri seseorang. Tokoh Rajo Alam Sati yang menduduki kekuasaan di Nagari Saribunian mempunyai istri yang bernama Puti Andam Dewi dan dianugerahi sepasang anak. Mereka bernama Bujang Gombang Alam dan Puti Ambun Suri. Ketika dilihat nasib Puti Ambun Suri oleh para dukun, ternyata Ambun Suri akan membawa bala petaka kepada kerajaan dan keluarganya. Mendengar hal yang demikian, terniat dalam diri Sang Raja Alam Sati untuk membunuh anaknya sendiri. Saat akan dibunuh oleh ayah sendiri, tiba-tiba datang Bujang Gombang Alam untuk melindungi adiknya yang masih kecil. Karena hal demikian yang terjadi, mereka pun pergi dari istana. 
"Mandanga ratok mandeh kanduang, lah tagak Si Gombang Alam, diambiak adiak di ribaan mandeh, dipangku jo kain cindai, sanan bakato maso itu," Adiak den usah dibunuah, bia bajalan kami baduo, adiak kandung balahan badan, antah pitanah dari lua, sabanyak urang nan sayang, sabanyak itu pula nan bangih," katonyo Si Gombang Alam, bakato sadang manangih, ayia mato badarai-darai, maliek adiak $k a$ dibunuah.

Maliek rupo nan bak kian, bakato Rajo Alam Sati, batitah sadang bangih, "Bajalan kalian kaduonyo, baok adiak ang masuak rimbo, tidak buliah dalam nagari. (KPNC, hlm: 22-23)

"Mendengar tangisan ibu kandung, langsung berdiri Si Gombang Alam, diambil adik dari pangukuan ibu, dipangku dengan kain cindai, disitu berkata ketika itu,’Adik saya jangan dibunuh, biar berjalan kami berdua, adik kandung belahan diri, tidak tahu bisikan dari luar, sebanyak orang yang saying, sebanyak itu pula yang marah," kata Si Gombang Alam, berkata sedang menangis, air mata berderai-derai, melihat adik akan dibunuh.

Melihat hal yang demikian, berkata Rajo Alam Sati, berkata sedang marah," berjalan kalian berdua, bawa adik kamu masuk hutan rimba, tidak boleh dalam nagari.

Dalam perjalanan, Bujang Gombang Alam dan Puti Ambun Suri merasakan kelaparan dan memutuskan untuk berhenti sejenak. Ketika berhenti Bujang Gombang berburu untuk mendapatkan makanan. Karena tidak ada api untuk pemangang, Bujang Gombang berjalan sejenak meninggalkan adiknya di hutan rimba. Ketika diperjalan mencari api, Gombang Alam melihat ladang jagung orang dan dia masuk keladang tersebut. Tidak disangka pemilik ladang melihat Gombang Alam. Diseranglah Gombang Alam hingga pingsan. Gombang Alam pun dibuang kelautan. Akhirnya mereka pun terpisah.

\section{MENDAMPINGI SUAMI}

Dalam kaba Siti Kalasun, terdapat peristiwa merantau yang disebabkan ingin menemani sang suami ditempat perantauan. Ternyata wanita ikut serta dalam peristiwa merantau. Pendapat ini diperkuat oleh Kato (Kato, 2005) yaitu faktor penyebab wanita ikut serta dalam proses merantau salah satunya karena semakin banyak laki-laki membawa istrinya serta anak-anak-anaknya ke daerah rantau.

"Lorong kapado Siti Kalasun, dibaok ka Banjarmasin, hiduik basuko tiok hari, badannyo gapuak putiah kuniang, sarupo jo nona Cino, tigo tahun di Banjarmasin, lah baranak duo urang, anak padusi kaduonyo." (KSK, hlm 86)

"Arah kepada Siti Kalasun, dibawa ke Banjarmasin, hiduik basuko tiok hari, badannya gemuk putih kuning, serupa dengan nona Cina, tiga tahun di Banjarmasin, sudah beranak dua orang, anak perempuan keduannya."

Dalam kaba Si Gadih Ranti, tokoh si Gadih Ranti juga pergi merantau untuk menemani suaminya yang bekerja di Padang. Setelah dua tahun di Padang, si Gadih Ranti melahir seorang anak laki-laki.

"Kan iyo si Gadih Ranti, dijapuik pulo dek Parmato, manatap di Padang, hiduik basuko hari, ado duo tahun perbauran, lahia anak laki-laki, baru baranak si Gadih Ranti, sanang hati Sutan Parmato, ubek jariah palarai damam, si dingin tahampa dikapalo." (KSGR, hlm: 83)

"Kan iya si gadih ranti, dijemput pula oleh Parmato, menetap di Padang, hidup bersuka hari, ada dua tahun perbaharuan, lahir anak laki-laki, baru beranak si Gadih Ranti, senang hati Sutan parmato, obat usaha penawar demam, si dingin terhampa dikepala." 


\section{Jurnal Elektronik WACANA ETNIK - Vol 8 No 1 April 2017, (1 - 12) \\ p ISSN 2089-8746, e ISSN 2302-7142}

Konsep merantau dikenal oleh berbagai kelompok etnis di Indonesia, mis., Boyanese, Jawa, Sudan, dan Minangkabau. Meskipun makna dari istilah ini telah ditafsirkan secara berbeda, pada umumnya menunjuk pada gerakan sementara untuk tujuan mencari pekerjaan dan perbaikan ekonomi, termasuk sirkulasi antar negara dan luar negeri (Spaan, 1994).

Orang Minangkabau mendasarkan keturunan matrilineal mereka dalam pandangan dunia yang lebih menekankan pada pengasuhan dan pertumbuhan daripada perjuangan. Perempuan lebih lemah, tentu saja, sehingga untuk melindungi keharusan memelihara, perempuan mewarisi rumah-rumah dan tanah tempat reproduksi ekonomi berada. Laki-laki muda didorong untuk merantau, yaitu untuk bermigrasi keluar dari jantung Minangkabau untuk mencari kekayaan dalam perdagangan atau cara lain, kadang-kadang kembali nanti untuk menetap di rumah tangga matrilineal yang diperluas dari istri mereka (Kipp \& Sanday, 2003).

Bagi orang Minangkabau, merantau jelas sebuah budaya yang teriinstitusi secara kompleks. Institusionalisasi tersebut adalah bagian dari perpindahan, baik permanen maupun tidak, yang terjadi tidak hanya dalam kelompok kesukuan tetapi juga dalam kelompok lokal dan regional (Salazar, 2016).

\section{PENUTUP}

Merantau di dalam kaba pada dasarnya dilatarbelakangi karena motif ekonomi, pendidikan, faktor sosial, berburu harta karun, dan menemani sang suami di perantauan. Dari sekian motif merantau, faktor yang mendominasi adalah faktor ekonomi dan profesi yang didalami oleh para pelaku merantau itu sendiri adalah berdagang.

Merantau merupakan suatu tradisi di Minangkabau yang wajib dilakukan oleh para laki-laki. Namun seiring berjalannya waktu, tradisi ini mulai terkikis. Peranan perempuan mulai terlihat dalam tradisi merantau ini. Kebanyakan dari perempuan yang merantau, dijemput oleh sang suami ketika sang suami pulang ke kampung halamannya.

\section{DAFTAR PUSTAKA}

Damono, S. D. (1979). Sosiologi Sastra Sebuah Pengantar. Jakarta: Pusat Pembinaan dan Pengembangan Bahasa. Faruk. (2003). Pengantar Sosiologi Sastra: dari Strukturalisme sampai Postmodernisme. Yogyakarta: Pustaka Pelajar.

Hadler, J. (2008). Sengketa Tiada Putus: Matriarkat, Reformisme Agama, dan Kolonialisme di Minangkabau. Jakarta: Freedom Institute.

Junus, U. (1984). Kaba dan Sistem Sosial Minangkabau: Suatu Problema Sosiologi Sastra. Jakarta: Balai Pustaka. Kato, T. (2005). Adat Minangkabau dan Merantau dalam Prespektif Sejarah. Jakarta: Balai Pustaka.

Kipp, R. S., \& Sanday, P. R. (2003). Women at the Center: Life in a Modern Matriarchy. Contemporary Sociology, 32(5), 562. https://doi.org/10.2307/1556463

McWilliam, A. (2009). The spiritual commons: Some immaterial aspects of community economies in eastern Indonesia. The Australian Journal of Anthropology, 20(2), 163-177. https://doi.org/10.1111/j.17576547.2009.00024.x

Naim, M. (2013). Merantau Pola Migrasi Suku Minangkabau. Yogyakarta: Gadjah Mada University Press.

Navis, A. A. (1984). Alam Takambang Jadi Guru: Adat Dan Kebudayaan Minangkabau. Jakarta: Grafiti Press.

Salazar, N. B. (2016). The (Im)Mobility of Merantau as a Sociocultural Practice in Indonesia. In N. G. Bon \& J. Repič (Eds.), Moving places: Relations, return and belonging. New York: Berghahn Books.

Sjarifoedin, A. (2014). Minangkabau. Jakarta: PT. Gria Media Prima.

Soekarto. (2013). Sosiologi Suatu Pengantar. Jakarta: PT RajaGrafindo Persada.

Spaan, E. (1994). Taikongs and Calos: The Role of Middlemen and Brokers in Javanese International Migration. 
Jurnal Elektronik WACANA ETNIK - Vol 8 No 1 April 2017, (1 - 12)

p ISSN 2089-8746, e ISSN 2302-7142

International Migration Review, 28(1), 93-113. https://doi.org/10.1177/019791839402800105 